\title{
Changing Attitudes Toward the Homeless: The Effects of Prosocial Communication With the Homeless
}

\author{
John E. Hocking ${ }^{1,3}$ and Samuel G. Lawrence ${ }^{2}$
}

One hundred, thirty-four undergraduate students participated in a field experiment designed to examine the effects of extended, prosocial communication with homeless persons, upon attitudes toward the homeless problem, of behavioral intentions towards the homeless, and of causal attributions about homelessness. It was expected that prosocial interaction with the homeless would produce shifts in attitudes and behavioral intentions toward the homeless and homelessness and result in greater attributions of external causes to explain homelessness. Nineteen experimental participants worked 15 hours at a local homeless shelter. Their responses to a posttest questionnaire that measured a range of attitudinal and behavioral orientations toward the homeless were compared with control participants who did not work at the shelter. Subsequent analyses furnished strong evidence of positive changes in attitudes and intentions toward homelessness among the shelter workers. These participants evaluated homeless people as less blameworthy and more socially attractive than did control participants; moreover, shelter workers indicated more personal responsibility and behavioral commitment to helping the homeless than control participants. They also perceived the homeless problem to be more serious and were more likely to attribute homelessness to bad luck than control participants. However, the two groups were equally likely to attribute homelessness to various external causes such as the economy, housing costs, and governmental policies. The results are interpreted as having policy implications for volunteer service.

KEY WORDS: attitude changes; homeless; homelessness; prosocial communication; behavioral intentions.

\footnotetext{
${ }^{1}$ University of Georgia, Athens, GA.

${ }^{2}$ University of Central Florida.

${ }^{3}$ Correspondence should be directed to John E. Hocking, Department of Speech Communication, University of Georgia, Terrell Hall, Athens, GA 30602; e-mail: Jhocking@Arches.uga.edu.
} 


\title{
INTRODUCTION
}

\begin{abstract}
What we have found in the country, and maybe we're more aware of it now, is one problem that we've had, even in the best of times, and that is the people who are sleeping in the grates, the people who are homeless you might say by choice.
\end{abstract}

—Ronald Reagan, 1984

Perhaps the single biggest obstacle impeding policy changes regarding treatment of the homeless is the fact that many, if not most, Americans have indifferent or even negative attitudes toward homeless people. These attitudes must be changed if progress toward eradication of homelessness is to be achieved. This research examined the effects of prolonged, prosocial interaction with the homeless on attitudes, behavioral intentions, and causal attributions concerning the homeless.

A central assumption is that those in a position to really help the homeless hold attitudes that range from indifference to outright hostility. Bahr (1973, p. 33-and we find no evidence of change; see Holden, 1997; Pellegrini, Queirolo, Monarrez, $\&$ Valenzuela, 1997) suggest that attitudes toward homeless men consist of:

[F]ive parts indifference, one part hostility, one part annoyance, and one part an amalgam of revulsion and morbid curiosity... [P]opular attitudes toward the homeless man, a rather diffuse stimulus, are a melange of attitudes toward more specific stimuli, especially the outlaw, the hobo or migrant worker, the drunk, the derelict and the stranger.

In short, many people subscribe to a range of stereotyped views of homeless people. Anecdotally, we have observed that the homeless person is typically male, lazy, morally bankrupt, and potentially dangerous. Because homelessness is seen largely as a character flaw rather than as a product of socioeconomic circumstances, homeless people are often held personally responsible for their plight.

One basis for these stereotyped perceptions may lie in a limited range of communicational experiences with homeless people (see Farrari, Loftus, \& Pesek, 1999; Morgan, Goddard, \& Givens, 1997). When communication with a particular group is limited, attitudes toward that group are shaped by its most visible members who, then, typify the group as a whole. Snow, Baker, Anderson, \& Martin (1986), for instance, argue that one basis for the wholesale attribution of mental illness to homeless people is the bizarre appearance of a small percentage of homeless people who are mentally ill. What little interaction takes place with the homeless serves to define them as an out-group rather than as individuals (Tajfel \& Turner, 1979). Stereotypes provide the primary means of uncertainty reduction (Berger \& Calabrese, 1975; Berger \& Bradac, 1982).

If stereotypes about the homeless stem from limited interaction experiences, then perhaps prolonged contact can furnish an alternative route to uncertainty reduction and change attitudes in a positive direction. The literature on the effects of interpersonal contact upon attraction to members of various out-groups is mixed (McGuire, 1985). Although interpersonal contact can intensify preexisting attitudes, prejudice toward out-groups tends to decrease when contact is long term, is 
voluntary, includes attractive members of the out-group, promotes the discovery of ideological similarities, emphasizes status equality, and involves a degree of personal intimacy. Thus, attitudes toward the homeless can be expected to shift in a positive direction when uncertainty reduction is based upon individual characteristics rather than upon group memberships.

In the present study, domiciled individuals worked at a local homeless shelter. Our expectation was that contact with homeless persons in this particular setting would produce positive changes in attitudes, behavioral intentions, and causal attributions. Several aspects of this contact buttress this expectation. First, although some homeless people are mentally ill and/or unattractive, others conduct themselves in intelligent and attractive ways. Some display a sense of humor, others do not. All have goals - at the least, finding a place to live. Prolonged interaction with homeless people is required to appreciate their individuated capacities, goals, and personalities. Second, contact with the homeless was extended. Shelter workers spent about 15 hours at the shelter. Third, the shelter environment deemphasizes status differences between shelter workers and the homeless. Shelter workers and homeless alike eat the same food, occupy the same quarters, engage in the same activities, and sleep on the same cots. Fourth, it is not uncommon for homeless persons to disclose how they became homeless, their hopes and dreams for the future, their religious beliefs, and other relatively intimate topics. Finally, working at the shelter was, at least to some extent, perceived by experimental participants as "voluntary." Together these factors are conducive to positive communicative experiences with the homeless.

Contrary to conventional wisdom, a single significant experience can have a profound effect upon attitudes. McGuire (1985, p. 254) writes that "studies of war neuroses, childhood traumas, political zealotry, critical-period imprinting, religious conversion, and product use, agree that a single significant experience can be critical." Three components of the shelter experience suggestive a powerful effect upon volunteers' attitudes and intentions toward the homeless. First, shelter workers are confronted with individuals whose life experiences differ dramatically from their own (Schachter, 1959). Second, shelter workers are confronted with multiple counter examples to the homeless person stereotype. Some have jobs; others are looking for jobs; some are intelligent, funny, and interesting; others are not. Some are female. Third, shelter workers engage in prosocial behavior vis a vis the homeless, assisting shelter residents in preparing meals, housekeeping, and organizing games.

Specifically, our predictions are that shelter workers would differ from control participants who did not work at the homeless shelter in the following respects:

H1: Shelter workers will report more positive attitudes toward homeless persons than control participants.

$\mathrm{H} 2$ : Shelter workers will report stronger behavioral intentions to help the homeless than control participants. 
H3: Shelter workers will perceive the homeless problem to be more serious than control participants.

H4: Shelter workers will attribute more importance to external causes of homelessness than control participants.

H5: Shelter workers will report more positive attitudes toward federal involvement in the homeless problem than control participants.

H6: Shelter workers will perceive their own personal problems to be less serious than control participants.

To test these predications, a field experiment in which a group of shelter workers spent a single night at a homeless shelter was conducted. Shelter workers interacted extensively with shelter residents, prepared and ate dinner and breakfast with them, and provided a measure of companionship. A comparable group of control respondents did not have this experience. Both experimental groups completed a variety of attitudinal, behavioral, and attributional measures. These data address the possibility that single extended episodes of prosocial communication with the homeless can have a impact dramatic impact upon participants views of the homeless.

\section{METHOD}

\section{Participants and Design}

The easiest way to examine the attitudes toward the homeless held by homeless shelter volunteers, compared to nonvolunteers, would be to simply measure and compare the attitudes in a sample of a each group. However, such an approach would be meaningless because selection bias' would constitute such a large alternative explanation for any differences between the groups that such an approach would lack internal validity. Those who freely volunteer to work at a homeless shelter are going to be more favorable toward this group than nonvolunteers. Our challenge was to create equivalent groups and then randomly have our experimental subjects work at the shelter and control subjects to not have this experience.

Participants included 131 undergraduate students at a university in the Southeastern United States. Nineteen shelter workers were enrolled in a required junior level course in empirical research methods in communication taught by one of the authors. A total of 112 control participants enrolled in undergraduate communication courses furnished four comparison groups: 31 control participants were enrolled in a separate section of research methods taught by a different instructor (control group 1a); 27 students in a section of communication theory constituted control group 1b. Twenty-seven students in a section of communication theory taught by a different instructor were control group 2. Twenty-seven students in a junior level nonverbal communication class comprised control group 3. 


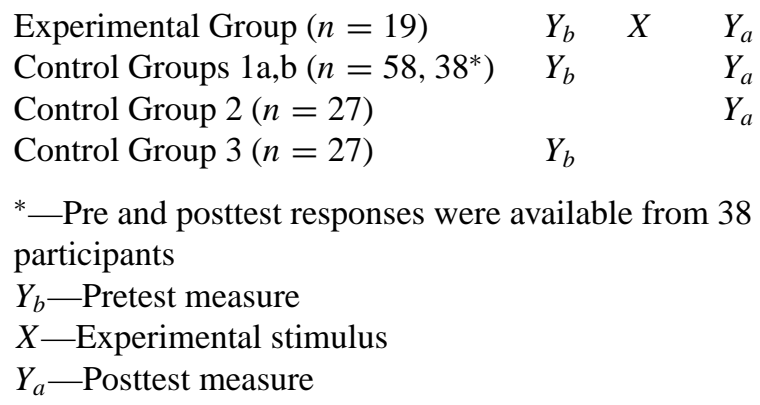

Fig. 1. The experimental design.

Participants in the experimental group and control groups $1 \mathrm{a}, 1 \mathrm{~b}$, and $3 \mathrm{com}-$ pleted a pretest questionnaire during the second class meeting of the term. Control group 2 did not complete a pretest questionnaire, and control group 3 did not complete any posttest measures. During the fifth, sixth, and seventh weeks of the term, male and female experimental participants were paired to work as shelter workers at the homeless shelter. Control groups 1a, 1b, and 2 completed the posttest questionnaire 24 hours after experimental participants completed their volunteer work. Thirty-eight of the participants in control group 1a and 1b completed both pretest and posttest measures. Thus, the 19 experimental subjects responses were compared to responses from 65 control group subjects. The design is displayed in Figure 1.

\section{Ensuring Equivalence: The Pretest Questionnaire}

For ethical reasons, random assignment of participants to conditions was precluded because the instructors could not arbitrarily require participation at the homeless shelter for some students while denying the opportunity to others. Because the use of intact classes as comparison groups was necessary, it was crucial to establish the initial equivalence of the control groups with the experimental group even though all individuals were drawn from precisely the same population: communication majors enrolled in junior level courses.

The experimental group and control groups 1a, 1b, and 3 completed a pretest questionnaire designed specifically to gather more evidence for initial equivalence. The questionnaire was presented as a university opinion survey that assessed opinions on a range of social issues. Participants rated on 10-point bipolar scales the national and local seriousness of nine social problems: AIDS, semi-automatic rifles, acid rain, the federal budget deficit, religious cults, the third world, date rape, drunk driving, and homelessness. Although it was especially important that the experimental and control groups not differ with respect to their perceptions of the homeless problem, the other eight social problems served two purposes. 
First, perceptions of the other eight social problems furnished additional evidence bearing on the equivalence of experimental and control groups. Second, the other social problems provided a context within which the critical homelessness items could be embedded, minimizing the risk of sensitizing participants to the issue of homelessness.

In addition, participants rated the seriousness of eight personal problems for themselves and for people generally: (1) "having enough money," (2) "boyfriend or girlfriend problems," (3) "getting good grades," (4) "being depressed," (5) "having trouble sleeping," (6) "getting a date for the coming weekend," (7) "being happy and satisfied with life," and (8) "having a nice place to live." The eighth problem was treated as another index of attitudes toward homelessness. The other seven personal problems furnished more equivalence data and served to minimize increased sensitivity to the homeless problems. Finally, participants reported their age, sex, grade point average, year in school, and social security number, which was used to match pretest and posttest responses for subsequent covariance analyses. Experimental participants were not told about the opportunity to work at the homeless shelter until 2 weeks after the pretest questionnaire had been completed.

\section{Solicitation of Shelter Workers}

Two considerations were balanced in obtaining participants for the experimental group. First, it was necessary to get the majority of students in the experimental class to "volunteer" to work at the homeless shelter. If a small proportion of shelter workers "volunteered" from this class, not only would this create a small sample size, but it would increase substantially the risk of selection biases. Perhaps only those participants who were favorably disposed toward the homeless would volunteer. The pretest questionnaire allowed assessments of this latter possibility; however, selection biases cannot be eliminated entirely as a rival explanation for observed differences unless most members of the class from which the experimental participants came indeed did "volunteer." Second, for both ethical and theoretical reasons, experimental participants were given the option to decline to work at the shelter. Recall that contact with members of an out-group is most likely to result in positive attitudinal changes when the contact is voluntary.

To deal with this delicate problem, students enrolled in the experimental class in research methods were given two term paper assignment options: (1) a content analysis option, and (2) a field research option. Both assignments required the submission of reports around 10 pages in length. The content analysis assignment required roughly the same amount of time as the field research assignment but was described in a plain, unappealing way on a three-page handout. The field research options required the student to spend one night at the local homeless shelter as participant-observers. Students were instructed to conceal their identities as field 
researchers and to give priority to their role as shelter "volunteer." In addition to meeting the educational objectives of the class, their subsequent reports served the dual functions of providing detailed information about the nature of the shelter experience and providing qualitative data about the effects of communicating with the homeless.

Both assignments were introduced at the beginning of the third week of the term. Students were given 2 days to choose a term project option. Afterwards, students signed a standard consent form that explained both options. Students who choose the field research option were unaware of their status as experimental participants. Twenty of 25 students chose the field research option. Nineteen of the 20 shelter workers actually worked at the shelter. Only the pretest scores of the 19 shelter workers were used to establish initial equivalence with the control groups.

\section{The Shelter Experience}

The shelter is located in a town with a population of about 80,000 in the southeastern United States. The shelter has been in operation for 2 years and at its present location for 5 months. The shelter is privately funded and staffed by one full-time and two part-time employees. After 5 p.m., a staff member and a male and female volunteer from the community supervise the preparation of meals, housekeeping chores, and recreational activities.

The shelter consists of a common area and bedrooms that are segregated by sex. A separate building accommodates families. The shelter has provided emergency shelter on extremely cold nights for up to 25 individuals, but the number of residents generally vary between eight and fifteen per night. The shelter's official policy is to deny admission to persons under the influence of drugs and/or alcohol, although occasional exceptions are made at the discretion of the staff member.

The shelter is open from 5 p.m. to 8 a.m. Shelter workers arrive at 5 p.m. and prepare the evening meal, sometimes assisted by guests. After the food has been served, shelter workers eat with the guests, wash dishes, and clean the dining area, with occassional assistance from guests. Shelter workers spend the remainder of the evening with the guests, sometimes playing cards, sometimes helping them fill out job applications, and almost always talking with the guests. The final task of the night involves setting up cots in the two bedrooms and in the common areas. Typically guests go to bed between 10 and 10:30 p.m. and sleep in the bedroom areas. Shelter workers sleep in the common area. At 6:30 a.m., both shelter workers and guests awaken and begin preparing breakfast. All guests are required to leave the shelter at 8 a.m.

An average of nine guests (six males and three females) were present at the shelter during that 2-week period of the experiment. Participant reports of events at the shelter revolved around a number of common experiences. Several shelter 
workers reported various forms of prosocial behavior among guests:

“As the volunteers, Dan and I weren't looking too forward to cleaning up. But as it turns out everyone pitched in. They were all so helpful, even though they were the guests they wanted to help out."

Another experimental participant wrote:

"The conversation for the evening consisted of where to look for jobs, when the guests thought they could leave, gossip about what had happened the night before and normal comments on what was going on in their lives. It was during this time that the participants opened up to us as volunteers. Because we were only going to be at the shelter for that evening, this facilitated the process of self-disclosure. Sometimes it is easier to tell a stranger than a friend.

Shelter workers reported enjoying the guests' company:

I remember with clarity how Fred told me about some of his adventures.... He told me about how he and his friends would hobo and ride the train. ... You couldn't help but laugh and enjoy Fred's past adventures.

Not every experience at the shelter, however, was positive. From time to time, unpleasant situations did arise:

Donna immediately grabbed three glasses of tea and poured it into her cup! When Ron asked her if she wanted any dinner, she cussed at him and began yelling. Then asked her to leave and when she refused, he called the police.

\section{The Posttest Questionnaire}

After completing their work at the shelter, shelter workers traveled to campus to meet with the instructor about writing the research report. Shelter workers were given the option of completing the posttest questionnaire or not. It was emphasized that their grade would in no way be affected by their choice and that their responses would be anonymous. All 19 shelter workers chose to fill out the posttest questionnaire. Shelter workers were instructed not to discuss any of their experiences at the shelter with other class members in order to avoid biasing others' field observations. Each worker signed a written agreement to discourage such discussions. Control participants completed the questionnaire within a day after experimental participants completed their work at the shelter.

The posttest questionnaire consisted of seven sections. In section 1, participants rated the seriousness of the homeless problem at the national, state, and local levels, and were asked to estimate the number of homeless people at each level. Section 2 measured behavioral intentions with respect to helping the homeless. Respondents indicated on 7-point scales the likelihood of performing a range of altruistic acts from "give clothes to a homeless shelter" to "allow a homeless person to move in with me until this individual could find a place to live." 
Section 3 utilized Likert type items to assess attitudes toward homeless people, personal responsibility for acting on behalf of homeless people, and attitudes toward federal and private intervention. Section 4 used semantic differential scales to measure attitudes toward homeless people (e.g., lazy vs. hardworking, mentally competent vs. mentally incompetent). Section 5 surveyed the relative importance of internal and external causes such as "bad luck," "the economy," among others. In Section 6, participants indicated the percentage of homeless people who fit various demographic characteristics such as "male," "drug addicts," "illiterates," and the like. In Section 7, participants again rated the perceived seriousness of eight personal problems for themselves and others as noted above. ${ }^{4}$

\section{Debriefing}

After all participants had completed the posttest questionnaire, thorough debriefings were held. Shelter workers were told that indeed their experiences at the shelter were an integral part of learning to do field research; however, in addition, the effects of the experience upon their views of the homeless were also of interest. Similarly, control participants were debriefed immediately after completing the posttest questionnaire.

\section{RESULTS}

\section{Initial Equivalence of Experimental Groups}

In order to establish the initial equivalence of the experimental groups, shelter workers and control groups 1a, 1b, and 3 were compared on 28 variables. Sex (power $=.93, .99)$, age, and grade point average (power $=.69, .96)$ did not distinguish shelter workers from control participants. ${ }^{5}$ In addition, the perceived seriousness of all nine social problems at the national and local levels did not differentiate shelter workers and controls (power $=.59, .91$ ). Seven of eight personal problems were rated as equally serious for shelter workers and controls (power $=.59$, .91). Shelter workers rated "being happy and satisfied with life" as a less serious problem for them than did control participants $(t(91)=-2.08, p<.042$, omega square $=.03)$ and "having a nice place to live" $(t(91)=2.43, p<.018$, omega square $=.05)$ as more serious problems for others than control participants.

Because only three of 28 pretest comparisons were significant, the experimental groups were considered to be equivalent for all practical purposes. However,

\footnotetext{
${ }^{4}$ Copies of the pretest and posttest questionnaires are available from the authors.

${ }^{5}$ All power estimates assume "medium" and "large" effect sizes (see Cohen, 1977). A one-tailed alpha of .05 was employed for all statistical analyses.
} 
this assumption requires some caution especially because the perceived seriousness of "having a nice place to live" for others was higher for shelter workers than for control participants. The three variables that differentiated shelter workers and noncontrol subjects were retained as possible covariates in the analysis of posttest data.

\section{Factor Analysis of Posttest Questionnaire}

Factor analyses using as principle axis method with varimax rotation were conducted to analyze five separate sections of the posttest questionnaire. Dividing the questionnaire into five sections was intended to increase the ratio of questionnaire items to respondents $(N=86)$. A first group of 16 items targeted respondents' attitudes toward homeless persons (e.g., "Most homeless people are not willing to take a steady job"). A second group of 16 items measured respondents' propensity to take action on behalf of the homeless (e.g., "I feel personally responsible for doing something about the homeless"). A third group of 12 items concerned perceptions of the homelessness problem itself (e.g., "Homelessness is among the most important social problems facing America today"). A fourth group of 11 items measured the amount of importance attributed to specific external causes of homelessness (e.g., bad luck, the job market, the economy). Finally a fifth group of 8 items concerned attitudes toward the involvement of the private and public sectors (e.g. "The efforts of churches and private citizens are more likely to solve the problem of homelessness than government intervention").

The number of factors was determined using Scree plots. Factors with eigenvalues less than 1.25 were not used as composite variables. Items were retained as part of a composite variable when the primary loading exceeded the highest secondary loading by 0.20 . Items with primary loadings of less than 0.50 or secondary loadings of more than 0.40 were not used as a part of a composite variable. ${ }^{6}$ Composite scores were based upon the summation of retained questionnaire items.

Factor analyses of items that targeted attitudes toward homeless persons yielded a two-factor solution. The first factor, blameworthiness, measured perceptions of homeless persons' responsibility for their plight (e.g. "Most homeless people choose to be homeless"). The second factor, social attractiveness, involved ratings of homeless persons' happiness, cleanliness, and thriftiness with money. Similarly a two-factor solution for items that measured respondents' willingness to act was obtained. Personal Responsibility assesses respondents' to view the problem of homeless as their own problem (e.g. "I feel personally responsible for doing something about homelessness"). Behavioral Commitment measures respondents' intentions to provide concrete social support for homeless persons (e.g. "Volunteer to spend time helping renovate low income housing so that a homeless family could have a place to live"). In addition, analyses of items that targeted the homeless problem yielded a single factor: perceived seriousness of homelessness.

\footnotetext{
${ }^{6} \mathrm{~A}$ report of the factor loadings is available from the authors.
} 
Finally, three factors emerged from items that measured perceptions of various external causes of homelessness. First, macrocauses of homelessness involved the amount of importance attributed to external causes of homelessness such as the economy, housing costs, and federal government policies. Second, items that assessed the perceived availability of jobs and housing (e.g. "It's too hard for homeless people to find adequate jobs and housing") emerged. Third, items that assessed the role of bad luck in the plight of the homeless formed the final factor. Finally, no coherent factors emerged from analyses of items concerning federal and private intervention.

\section{Reliability Estimates}

Alpha coefficients were computed for all composite variables. The average alpha coefficient was 0.76 . Table I shows the alpha coefficents, means, standard deviations, and $t$ values for the experimental and control group comparison for all composite variables.

\section{Posttest Comparisons of Experimental Groups}

One-way ANOVAs were computed for each dependent variable. Three planned orthogonal comparisons were employed to partition the systematic variance.

Table I. Alpha Coefficients, Means, Standard Deviations, and $t$ Values for All Composite Variables

\begin{tabular}{lcrrc}
\hline \multicolumn{1}{c}{ Variable } & Alpha & Shelter & & \\
& $M S D$ & $M S D$ & Control & $t$ \\
\hline Blameworthiness & .88 & 29.94 & 24.44 & $4.27^{* * *}$ \\
& & 4.04 & 5.00 & \\
Attractiveness & .75 & 13.44 & 9.04 & $6.16^{* * *}$ \\
& & 2.66 & 2.69 & \\
Personal responsibility & .81 & 26.72 & 21.82 & $5.15^{* * *}$ \\
& & 2.70 & 3.74 & \\
Behavioral commitment & .75 & 13.28 & 10.10 & $3.26^{* * *}$ \\
& & 4.18 & 3.67 & \\
Perceived seriousness & .85 & 27.89 & 24.65 & $2.92^{* *}$ \\
& & 2.72 & 4.49 & \\
External causes of & .66 & 28.72 & 26.52 & $1.73^{*}$ \\
$\quad$ homelessness & & 3.48 & 4.98 & \\
Bad luck & .71 & 14.22 & 12.38 & $2.39^{* *}$ \\
& & 3.14 & 2.85 & \\
Availability of jobs & .85 & 12.78 & 11.00 & $2.41^{* *}$ \\
$\quad$ and housing & & 2.46 & 2.80 & \\
\hline
\end{tabular}

Note. $D f$ s range from 80 to 82 .

${ }^{*} p<.05$.

$* * p<.01$.

${ }^{* * *} p<.001$. 
Table II. Means, Standard Deviations, and $t$ Values for Behavioral Intentions Data

\begin{tabular}{|c|c|c|c|}
\hline Variable & $\begin{array}{l}\text { Shelter } \\
M S D\end{array}$ & $\begin{array}{l}\text { Control } \\
M S D\end{array}$ & $t$ \\
\hline $\begin{array}{l}\text { 1. Volunteer to serve as a } \\
\text { "sponsor" for a homeless } \\
\text { person and provide them } \\
\text { with moral support, } \\
\text { counseling, help finding } \\
\text { a job, and a place to live. }\end{array}$ & $\begin{array}{l}5.17 \\
1.62\end{array}$ & $\begin{array}{l}3.84 \\
1.55\end{array}$ & $3.40^{* * *}$ \\
\hline $\begin{array}{l}\text { 2. Allowing a homeless } \\
\text { person to move in with } \\
\text { me until this individual } \\
\text { could find a place to live. }\end{array}$ & $\begin{array}{l}3.28 \\
1.49\end{array}$ & $\begin{array}{l}2.16 \\
1.30\end{array}$ & $3.28^{* *}$ \\
\hline $\begin{array}{l}\text { 3. Volunteer to spend time } \\
\text { helping renovate low } \\
\text { income housing so that } \\
\text { a homeless family could } \\
\text { have a place to live. }\end{array}$ & $\begin{array}{l}4.83 \\
1.49\end{array}$ & $\begin{array}{l}3.69 \\
1.30\end{array}$ & 1.62 \\
\hline $\begin{array}{l}\text { 4. Spend a night as a volunteer } \\
\text { at a homeless shelter. }\end{array}$ & $\begin{array}{l}6.39 \\
0.85\end{array}$ & $\begin{array}{l}3.69 \\
1.75\end{array}$ & $6.57^{* * *}$ \\
\hline $\begin{array}{l}\text { 5. Persuade others to get } \\
\text { involved in helping the } \\
\text { homeless. }\end{array}$ & $\begin{array}{l}4.17 \\
0.71\end{array}$ & $\begin{array}{l}2.91 \\
0.60\end{array}$ & $7.61^{* * *}$ \\
\hline $\begin{array}{l}\text { 6. Vote for a candidate } \\
\text { who was going to make } \\
\text { ending homelessness a } \\
\text { very high priority for } \\
\text { the federal government. }\end{array}$ & $\begin{array}{l}6.22 \\
1.00\end{array}$ & $\begin{array}{l}5.15 \\
1.56\end{array}$ & $2.80^{* *}$ \\
\hline $\begin{array}{l}\text { 7. Give money to a group } \\
\text { whose goal was to help } \\
\text { the homeless. }\end{array}$ & $\begin{array}{l}5.28 \\
1.74\end{array}$ & $\begin{array}{l}4.82 \\
1.68\end{array}$ & 0.96 \\
\hline $\begin{array}{l}\text { 8. Give old clothes to a } \\
\text { homeless shelter. }\end{array}$ & $\begin{array}{l}6.50 \\
0.99\end{array}$ & $\begin{array}{l}6.37 \\
1.01\end{array}$ & 0.53 \\
\hline
\end{tabular}

Note. $d f \mathrm{~s}$ range from 80 to 82 .

${ }^{*} p<.05$.

${ }^{* *} p<.01$.

${ }^{* * *} p<.001$.

First, a comparison of shelter workers with control groups 1a, 1b, and 2 furnished direct tests of hypotheses H1 through H6. Second, control group 2 was contrasted with groups $1 \mathrm{a}$ and $1 \mathrm{~b}$ to assess the effect of pretesting upon posttesting scores. ${ }^{7}$ Third, control group 1a was compared with control group 1b. ${ }^{8}$ Fourth, ANCOVAs using pretest scores as covariates served to test the robustness of obtained effects. ${ }^{9}$ Finally, $t$ tests comparing shelter workers behavioral intentions with those of the control subjects were performed. Table II displays these results.

${ }^{7}$ Only $7 \%$ (5 of 69) of these posttest comparisons were significant, suggesting that the pretest did not sensitize participants to the issue of homelessness.

${ }^{8}$ Only 3\% (2 of 69) of these posttest comparisons were significant, suggesting that course content and/or instructors had no bearing on the attitudes toward the homeless.

${ }^{9}$ Covariance analyses were carried out when a pretest measure exhibited a correlation of at least 0.50 with the posttest measure (Huitema, 1980, p. 126). 


\section{Attitudes Toward Homeless People}

Hypothesis $\mathrm{H} 1$ predicted that shelter workers would exhibit more positive attitudes toward homeless people than control participants. As shown in Table I, this hypothesis was confirmed. Shelter workers rated homeless people as less blameworthy $(t(80)=4.27, p<.001$, omega square $=.17)$ and as more attractive $(t(82)=6.15, p<.001$, omega square $=.30)$ than did controls. Shelter workers were less likely to perceive homeless people as dangerous to others $(t(80)=3.94$, $p<.001$, omega square $=.15)$, at fault for their homelessness $(t(82)=3.10, p<$ .002 , omega square $=.09)$, and more likely to perceive homeless people as basically good $(t(82)=5.82 . p<.001$, omega square $=.28)$, as similar to them $(t(82)=$ $3.70, p<.001$, omega square $=.13)$, as intelligent $(t(82)=2.55, p<.007$, omega square $=.06)$, and as deserving sympathy $(t(81)=1.71, p<.05$, omega square $=$ $.02)$ than controls. Shelter workers and control participants attributed comparable amounts of good judgment and common sense, mental competence, and moral character to homeless people (power $=.58, .90)$.

\section{Personal Responsibility and Behavioral Commitment}

Hypothesis $\mathrm{H} 2$ predicted that shelter workers would ensure more personal responsibility for homelessness and exhibit stronger intentions to act than controls. This hypothesis was confirmed, as shown in Table I. Shelter workers reported higher levels of personal responsibility $(t(80)=5.15, p<.001$, omega square $=$ .32 ) and behavioral commitment $(t(82)=3.26, p<.001$, omega square $=.10)$.

As shown in Table II, shelter workers reported more willingness to persuade others to get involved in helping the homeless $(t(81)=7.61, p<.001$, omega square $=.40)$, to spend a night as a volunteer at a homeless shelter $(t(82)=6.57$, $p<.001$, omega square $=.33$ ), to vote for candidates who were committed to making homelessness a priority for the federal government $(t(82)=2.80, p<.004$, omega square $=.07$ ), to allow a homeless person to move in with them until they can find a place to live $(t(82)=3.28, p<.001$, omega square $=.10)$, and volunteer to serve as a "sponsor" for a homeless person $(t(82)=3.40, p<.001$, omega square $=.12$ ). Shelter workers also reported (again, Table II) having more time to help homeless people $(t(82)=2.73, p<.004$, omega square $=.07)$, and as more sympathetic toward homeless people $(t(81)=2.16, p<.018$, omega square $=.04)$. Table II also shows that shelter workers and control participants reported comparable willingness to give clothes and money to help the homeless (power $=.58, .90)$.

\section{Perceived Seriousness of Homelessness}

Hypothesis $\mathrm{H} 3$ predicted that shelter workers would perceive homelessness to be a more social problem than control participants, and, as shown in Table I, this hypothesis was confirmed $(t(82)=2.92, p<.003$, omega square $=.08)$. Using the 
perceived seriousness of homelessness nationally as a covariate did not diminish differences between shelter workers and controls.

\section{Causal Attributions}

Hypothesis $\mathrm{H} 4$ predicted that shelter workers would be more likely to attribute homelessness to external causes than control participants. This hypothesis received partial support. Examination of Table I reveals that shelter workers attributed more importance to luck $(t(82)=2.39, p<.01$, omega square $=.03)$ and to a lack of jobs and housing $(t(2.41, p<.01$, omega square $=.05)$ as causes of homelessness than controls. Shelter workers attributed more importance to a composite of various external causes of homelessness $(t(82)=1.74, p<.043$, omega square $=.02)$; however, this difference was due to a single external cause, "break up of the family" $(t(82)=3.40, p<.001$, omega square $=.11)$. The remaining external causes did not distinguish shelter workers and control participants) power $=.58, .90$ ).

\section{Public and Private Intervention}

Hypothesis H5 predicted that shelter workers would be more favorably disposed toward federal intervention to solve homelessness. This hypothesis was partially confirmed. Shelter workers perceived federal intervention as more integral to solving homelessness $(t(82)=3.94, p<.001$, omega square $=.15)$, and as being more likely to succeed than fail $(t(82)=2.73, p<.005$, omega square $=$ .07) than controls. On the other hand, shelter workers and control participants did not differ on the relative effectiveness of public versus private intervention (power $=.58, .90)$.

\section{Perceived Seriousness of Personal Problems}

Hypothesis H6 predicted that shelter workers see their own personal problems as less serious and others' personal problems as more serious than control participants. As shown in Table III, this hypothesis was not confirmed. Shelter workers rated "having enough money" $(t(81)=-2.46, p<.009$, omega square $=.06)$, "being depressed" $(t(81)=-2.29, p<.013$, omega square $=.05)$, and happy and satisfied with life" $(t(81)=-3.03, p<.002$, omega square $=.09)$ as less serious personal problems for them than did control participants. However, when pretest scores were used as covariates, shelter workers did not differ from controls on all three variables (power $=.36, .73$ ).

Table III also indicates that shelter workers and control participants did not differ on the perceived seriousness of boyfriend or girlfriend problems, getting good grades, having a nice place to live, insomnia, and getting a date for the weekend for themselves (power $=.58, .90$ ). 
Table III. Pretest-Posttest Correlations, Means, Standard Deviations, and $t$ Values for Personal Problems Data

\begin{tabular}{|c|c|c|c|c|}
\hline Variable & $r$ & $\begin{array}{l}\text { Shelter } \\
M S D\end{array}$ & $\begin{array}{c}\text { Control } \\
M S D\end{array}$ & $t$ \\
\hline \multirow{2}{*}{$\begin{array}{l}\text { 1. Having a nice place } \\
\text { to live, for you } \\
\text { personally }\end{array}$} & \multirow[t]{2}{*}{.64} & 7.44 & 7.82 & \multirow{2}{*}{-0.69} \\
\hline & & 2.03 & 2.06 & \\
\hline \multirow{2}{*}{$\begin{array}{l}\text { 2. Having a nice place } \\
\text { to live, for people } \\
\text { in general }\end{array}$} & \multirow[t]{2}{*}{.13} & 8.11 & 7.37 & \multirow[t]{2}{*}{$2.00^{*}$} \\
\hline & & 1.28 & 1.36 & \\
\hline \multirow{2}{*}{$\begin{array}{l}\text { 3. Being happy and } \\
\text { satisfied with life, } \\
\text { for you personally }\end{array}$} & \multirow[t]{2}{*}{.57} & 7.28 & 8.99 & \multirow[t]{2}{*}{$-3.03^{* *+}$} \\
\hline & & 3.41 & 1.55 & \\
\hline \multirow{2}{*}{$\begin{array}{l}\text { 4. Being happy and } \\
\text { satisfied with life, } \\
\text { for people in general }\end{array}$} & \multirow[t]{2}{*}{.48} & 9.11 & 8.15 & \multirow[t]{2}{*}{$2.37^{*}$} \\
\hline & & 0.76 & 1.67 & \\
\hline \multirow{2}{*}{$\begin{array}{l}\text { 5. Having enough money, } \\
\text { for you personally }\end{array}$} & \multirow[t]{2}{*}{.63} & 6.22 & 7.61 & \multirow[t]{2}{*}{$-2.46^{*+}$} \\
\hline & & 2.69 & 1.97 & \\
\hline \multirow{2}{*}{$\begin{array}{l}\text { 6. Having enough money, } \\
\text { for people in general }\end{array}$} & \multirow[t]{2}{*}{.24} & 7.72 & 7.34 & \multirow[t]{2}{*}{0.85} \\
\hline & & 1.36 & 1.70 & \\
\hline \multirow{2}{*}{$\begin{array}{l}\text { 7. Boyfriend or girlfriend } \\
\text { problems, for you } \\
\text { personally }\end{array}$} & \multirow[t]{2}{*}{.39} & 5.17 & 6.10 & \multirow{2}{*}{-1.32} \\
\hline & & 3.02 & 2.44 & \\
\hline \multirow{2}{*}{$\begin{array}{l}\text { 8. Boyfriend or girlfriend } \\
\text { problems, for people in } \\
\text { general }\end{array}$} & \multirow[t]{2}{*}{.14} & 6.78 & 6.48 & \multirow[t]{2}{*}{0.61} \\
\hline & & 1.48 & 2.00 & \\
\hline \multirow{2}{*}{$\begin{array}{l}\text { 9. Getting good grades, } \\
\text { for you personally }\end{array}$} & \multirow[t]{2}{*}{.64} & 8.17 & 8.05 & \multirow[t]{2}{*}{0.30} \\
\hline & & 2.07 & 1.65 & \\
\hline \multirow{2}{*}{$\begin{array}{l}\text { 10. Getting good grades, } \\
\text { for college students } \\
\text { in general }\end{array}$} & \multirow[t]{2}{*}{.23} & 7.89 & 7.78 & \multirow[t]{2}{*}{0.29} \\
\hline & & 1.91 & 1.51 & \\
\hline 11. Being depressed, for & .58 & 4.78 & 6.43 & $-2.29^{*+}$ \\
\hline you personally & & 3.08 & 2.52 & \\
\hline 12. Being depressed, for & .27 & 7.83 & 7.40 & 1.13 \\
\hline people in general & & 1.58 & 1.80 & \\
\hline 13. Insomnia, for you & .53 & 4.11 & 5.12 & -1.17 \\
\hline personally & & 3.09 & 3.01 & \\
\hline 14. Insomnia, for people & .47 & 7.00 & 6.28 & $1.65^{*}$ \\
\hline in general & & 1.53 & 1.91 & \\
\hline 15. Getting a date for & .63 & 3.44 & 3.60 & -0.12 \\
\hline $\begin{array}{l}\text { the coming weekend, } \\
\text { for you personally }\end{array}$ & & 2.92 & 2.48 & \\
\hline 16. Getting a date for the & .34 & 6.83 & 5.69 & $2.10^{*}$ \\
\hline $\begin{array}{l}\text { coming weekend, for } \\
\text { people in general }\end{array}$ & & 1.76 & 2.11 & \\
\hline
\end{tabular}

Note. $d f \mathrm{~s}$ range from 80 to 82 .

${ }^{+}$These differences were eliminated in the covariance analyses.

$* p<.05$.

*** $p<.01$.

${ }^{* * *} p<.001$. 


\section{DISCUSSION}

These data support the thesis that prosocial interaction with the homeless can result in positive changes in attitudes, beliefs, and behavioral intentions toward the homeless. Shelter workers were less likely to judge the homeless as blameworthy and unattractive than individuals in the control groups. Shelter workers viewed the homeless problem as more serious. Perhaps most importantly, volunteers reported higher levels of behavioral commitment toward the homeless. Findings concerning causal attributions were not as strong as the attitudinal findings. Although shelter workers were more likely to attribute importance to bad luck and the job market than nonvolunteers, both groups attached comparable importance to other external causes, such as the economy, governmental policies, and selfishness in society. Our expectation that shelter workers would see their own personal problems as less severe than would control participants was not confirmed. When pretest scores were used as covariates, the effects of volunteering at the shelter on self perceptions of the severity of personal problems became nonsignificant.

Taken as a whole, the results provide clear evidence that a single positive experience with the homeless can result in substantial changes in how these individuals are viewed. The strength of the findings range from impressive, in which 30 to $40 \%$ of the variance of some dependent variables was accounted for by a single shelter experience, to weak, in which omega square values of 0.02 to 0.05 were obtained. The strongest findings concerned shelter workers willingness to persuade others to become involved with the homeless (omega square $=.40$ ), reports of feelings of personal responsibility to help the homeless (omega square = .33 ), judgments of the attractiveness of homeless individuals (omega square $=.30$ ), perceptions of the seriousness of the problem nationally (omega square $=.33$ ), and perceptions of homeless people as "good" (omega square $=.28$ ). Considering that these estimated effect sizes are attributable to a single manipulated independent variable, the figures are unusually large. They support the conclusion that the shelter experience was a powerful stimulus, at least in terms of effects on these dependent variables.

Moderate findings were also found for comparisons between volunteer and control participants on ratings of homeless people as blameworthy (omega square $=.17$ ), dangerous to others (omega square $=.13$ ), similar to them (omega square $=.13$ ), and on the importance of federal government intervention in solving the problem (omega square $=.15$ ). Other findings, particularly those concerning attributions of responsibility for homelessness, were modest to weak, with variance accounted for estimates in the 2 to $7 \%$ range. No significant differences were found, or were washed out in subsequent covariance analyses, for perceptions of homeless persons' common sense, mental competence, and good judgment. There also were no differences in perceptions of the demographic makeup of the homeless, the perceived importance of causes of homelessness, or the relative effectiveness of private and governmental solutions. 
Regarding the behavioral intention measures, which we believe to be particularly important because of their implications for actual behavioral changes, its is interesting to note that there were no differences between shelter workers and controls on most of the "easy" behaviors; but the two groups did differ on their stated intentions of engaging in the moderately involving behaviors and in the most difficult behaviors. For example, shelter workers and control participants did not differ significantly in their stated intentions to give clothing or money to a homeless shelter (both relatively easy to do) but they did differ in their indicated willingness to persuade others to help with the problem, spending the night at a homeless shelter (both requiring moderate investments of time and energy), and in their reported likelihood of "sponsoring" a homeless person and in allowing a homeless person to move in with them on a short term basis (both requiring substantial resource investments). It appears that most participants, whether in the experimental or the control group, indicated a fairly high intention of engaging in many of the "easy" behaviors. It was in the area of moderate and difficult behaviors where the shelter experience appears to have had the largest impact.

\section{Qualitative Data}

Qualitative data were available to supplement subjects' responses to the posttest questionnaire. As noted, each experimental participant wrote a paper about their experiences. Their written reports are completely consistent with the quantitative results. For example, one participant noted:

More care, more attention, and more natural love are needed for the people in this country with no place to go.

Another commented on the impact of visiting the shelter and the value of the experience:

a day or two went by and all I could do was think about my stay at the shelter and everyone there.... What being a volunteer meant to me was not so much the physical duties of cooking and cleaning, but more the companionship I was able to give these people. It was perhaps the easiest as well as the most rewarding task I have ever experienced.

A number of participants noted explicit changes in their perceptions of the homeless and in the cause of homelessness. The following excerpts are representative:

The homeless are productive individuals fighting hard to break their ties with the shelter. They are looking for jobs and trying to rebuild their lives. I want to erase the stereotype of the lazy, ungrateful homeless. With my experience as a volunteer, I know now that they have the same hopes and ambitions as we do.

Our entertainment that evening was simply talking to each other.... There were no constraints between volunteer and guest. We were equals... The conversations continued and we got to know each other better as time passed. During these talks is when I came to my conviction that the homeless were misrepresented. No they are not lazy and unproductive. 
They are here because of unfortunate circumstances. They want to work, they want to become productive citizens.... The stereotype of the homeless is so wrong and so untrue. They are here due to situations out of their control.

\section{Implications}

An indisputable fact as we end the last decade of the twentieth century is that individual Americans are being asked to do more for their communities, for their country, and for one another. Particularly beginning with the 1988 presidential campaign, candidate George Bush repeatedly referred to "a thousand points of light spreading across the landscape like stars," as a metaphor for volunteerism and community service. He was referring to individuals doing more, while government does less. Of course, President Clinton's views on the importance of volunteerism are well known. Whether we agree with these views or not, the evidence seems indisputable that the long term trend is toward less government involvement in solving some of our most serious social problems. Since the 1996 election, the president has become more explicit in his call for national service. Although President Clinton envisions increased volunteerism as a result of both altruistic and monetary incentives, others have suggested inducing some form of community service in other ways. For example, increasingly, nonviolent criminals have been required, as part of their sentences, to engage in a specified number of hours in such activities (see McCarthy and Bernadr, 1984).

What are and will be the efforts of voluntary and mandatory participation in such services on participants? How will the beliefs, attitudes, and subsequent behaviors of participants be affected by exposure to stigmatized groups such as the poor, the mentally retarded, the aged, the physically disabled, or the homeless? The results of the present experiment suggest that this kind of service can have very positive effects on those involved. Additional research is needed to determine the effects of other kinds of community service, and on how the experience might be structured so as to maximize beneficial outcomes. For example, to what extent are effects influenced by whether the service is a result of volunteerism or motivated by government money for college, as compared to community service mandated by a court of law.

\section{Limitations and Caveats}

Our participants served as shelter workers at a well-run homeless shelter in a medium-sized community. We do not know if their experiences were representative of other shelters. Possibly, the extremely positive effects shown in the present study might be mitigated by a shelter that was large and more impersonal. Also, this shelter does not normally allow individuals who have been drinking alcohol 
or who are on drugs to spend the night. Viewed most conservatively, the findings probably constitute good evidence of what can happen in a well-run, volunteerstaffed shelter.

The instructor of the class from which the experimental subjects came was also one of the authors. In spite of the fact that the posttest questionnaire was completed anonymously, this may have created experimenter demand characteristics that contributed to the strength of the findings reported. However, if demand characteristics were accounting for the results, it seems likely that all variables would have been affected. In fact, no significant differences between experimental and control participants were found for a substantial number of the variables.

In addition to being subjects in an experiment, our participants were students fulfilling a class assignment. Although our participants were explicitly instructed to be shelter workers first, the kinds of observations they made and the effects of the experience on their attitudes may have been influenced by these dual roles. Possibly, shelter workers who were not also participant/observers engaged in a classroom research project would have been affected differently.

Subjects completed the posttest questionnaire the day after spending the night at the shelter, and this timing may have resulted in measuring the dependent variables when the shelter experience was most powerful. The dramatic changes we observed may dissipate with time for many of the participants. Of course, it is also possible that the effects will increase with time, at least for some. The experience could cause experimental participants to attend more carefully to media treatment of the problem, or, in a few cases, even to become involved actively with the homelessness problem, which, in turn, could reinforce and accentuate the results reported. In fact, one of the participants in the experimental group subsequently visited the shelter several times as a volunteer on her own and recently began assisting in the editing of the shelter newsletter.

\section{CONCLUSION}

The purpose of the experiment reported here was to examine the effects of communication with homeless individuals on subsequent attitudes toward these individuals and their situation. It is through communication that uncertainty about what other people are like is reduced. When communication is absent, uncertainty will be high and attitudes will be shaped by casual observations, by superficial media treatments, by the statements of politicians, and by our personal philosophies and prejudices. Most Americans do not know anyone who is homeless, have never talked to homeless people, never heard their accounts of why they are homeless, of what circumstances have resulted in their plight, of what it is like to be homeless, or of whether they are similar or different than people with a place to live. When interpersonal communication with a particular group permits us to come to know group members as individuals, rather than as stereotypes, our attitudes may 
change. When we learn, through direct contact and communication, that homeless individuals are not different from us in any fundamental way and that they have thoughts, self-esteem, hopes, sadness, and all the other human emotions that we have, our attitudes and behaviors toward these individuals may change. Indifference and complacency may not only be reduced, but also may be prefaced by involvement and caring. The present experiment fully supports this conclusion.

\section{REFERENCES}

Behr, H. (1973). Skid row: An introduction to disaffiliation. New York: Oxford University Press.

Berger, C. R., \& Calabrese, R. J. (1975). Some explorations in initial interactions and beyond: Toward a developmental theory of interpersonal communication. Human Communication Research, 1, 99-112.

Berger, C. R., \& Bradac, J. J. (1982). Language and social knowledge: Uncertainty in interpersonal relations. London: Edward Arnold.

Cohen, J. (1977). Statistical power analysis in the behavioral sciences. (rev. ed.). New York: Academic Press.

Ferrari, J. R., Loftus, M. M., \& Pesek, J. (1999). Young and older caregivers at homeless and animal shelters: Selfish and selfless motives in helping others. Journal of Social Distress and the Homeless, 8, 37-49.

Holden, D. (1997). On equal ground—sustaining virtue among volunteers in a homeless shelter. Journal of Contemporary Ethnography, 26, 117-145.

Huitema, B. E. (1980). The analysis of covariance and alternatives. New York: John Wiley \& Sons.

McCarthy, B. R., \& McCarthy, B. (1984). Community-based collections. Monterey, CA: Brooks/Cole.

McGuire, W. J. (1985). Attitudes and attitude change. In G. Lindzey \& E. Aronson (Eds.), The handbook of social psychology, 3rd ed. (pp. 233-346). Hillsdale, New Jersey: Lawrence Erlbaum Associates.

Morgan, M. M., Goddard, H. W., \& Givens, S. N. (1997). Factors that influence willingness to help the homeless, Journal of Social Distress and the Homeless, 6, 45-56.

Pellegrini, R. J., Queirolo, S. S., Monarrez, V.E., \& Valenzuela, D. M. (1997). Political identification and perception of homelessness-Attributed causality and attitudes and public policy. Psychological Reports, 80, 1139-148.

Schactner, S. (1959). The psychology of affiliation. Palo Alta, CA: Stanford University Press.

Snow, D. A. Baker, S. G. Anderson, L., \& Martin, M. (1986). The myth of persuasive mental illness among the homeless. Social Problems, 33, 407-423.

Taijfel, H., \& Turner, J. C. (1979). An integrative theory of intergroup conflict. In W. G. Austin \& S. Worchel (Eds.), The social psychology of intergroup relations. Monterey, CA: Brooks/Cole. 